\title{
On tobacco industry cultural appropriation
}

\section{Ruth E Malone}

The cover of this issue features Santa Claus images from the travelling exhibition, "Merry X-Ray and A Happy New Lung: When Santa Sold Cigarettes", created by Alan Blum, Director of the University of Alabama Center for the Study of Tobacco and Society. Taken from popular magazines published in the US, these images feature Santa, one of the most ubiquitous symbols of the Christmas season, suggesting cigarettes as a giftcertainly one that gave so many recipients and their families the "gift" of disease, suffering, premature death and much heartache. I am confident, however, that even in countries where Christmas is not celebrated so widely or at all, we could find examples linking cigarettes or other tobacco products with numerous respected or revered symbols and images. Such examples illustrate cultural appropriation, which in marketing involves the exploitation of culturally significant images, activities, practices and values to sell products.

An important concept in cultural appropriation is the idea of a cultural "invader". According to one writer, "Invaders arrive without warning, take whatever they want for use in whatever way they see fit. They destroy without thinking anything that appears to them to be valueless. They stay as long as they like, leave at their own convenience. Theirs is a position of entitlement without allegiance". ${ }^{1}$ Tobacco companies are possibly the first and arguably the ultimate corporate cultural invaders, relentlessly seeking to link their products to every conceivable cultural symbol, icon and image. These include, but are not limited to nurses and doctors as symbols of purity and health, sports figures as symbols of vigour, babies and children as symbols of harmlessness/innocence, Native Americans and other indigenous groups as symbols of authenticity, military images as symbols of toughness, landmarks as symbols of the exotic or the enduring. Images such as those accompanying this editorial

Correspondence to: Ruth E Malone, Department of Social \& Behavioral Sciences, University of California, San Francisco, California, 94118, USA; ruth.malone@ucsf. edu (figs 1-4), taken from the Stanford University collection of 20th century tobacco advertisements, "Not a cough in a carload" (http://lane.stanford.edu/ tobacco/index.html), also exemplify this phenomenon. Truly, nothing is sacredincluding the sacred. A few years ago, this was illustrated by a Tobacco Control piece on cigarette calendars from the Philippines featuring the Virgin Mary. ${ }^{2}$

However, it is not only in advertising that tobacco industry cultural appropriation occurs. It also happens when companies engage in so-called "corporate social responsibility" activities that serve to link them with "good causes" that are highly valued in society. It happens when nongovernmental organisations that do not see themselves as having a role to play in public health join in "partnerships" with the tobacco industry, lending the industry their image and credibility. ${ }^{3}$ It happens every time a child wears a cigarettebranded item, a musician features smoking in a video, a pack of cigarettes bears patriotic colours, a team is sponsored by a tobacco company, or an edgy movie or play features smoking. Our families, our music, our art, our aspirations-all are harnessed in the service of selling more tobacco.

Why does this matter? Obviously, on a practical level, anything that furthers tobacco use matters for public health because the cigarette is the single most deadly consumer product ever made. Tobacco killed staggering numbers during the last century and is projected by the World Health Organization to kill a billion people in this century if trends continue. ${ }^{4}$

But it should also matter to everyone who cares about preserving a life-world where human experiences of beauty, love, friendship, compassion and joy can be shared without the obtrusion of product marketing.

Several years ago, seeing somewhere a photograph of the American West with a sunset desert scene, I suddenly realised that as a result of growing up in the era of the Marlboro Man, such a scene was now already "branded" for me. For me, and I am sure for many others of my generation, the entire landscape of the West had
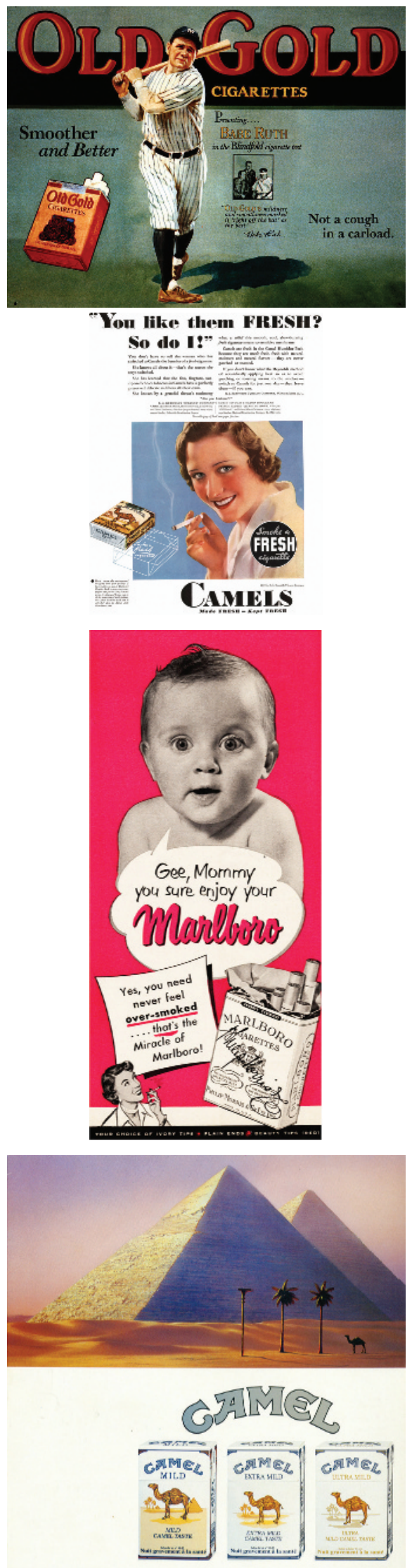

FUMER PROVOQUE DES MALAOIES GRAVES

Figures Cigarette advertising courtesy Stanford University collection (http://lane. stanford.edu/tobacco/index.html). 
been hijacked-so that to view a particular kind of picture of it was to evoke the world's top premium cigarette brand-a brand that linked images of freedom and wide open spaces with an addictive product that causes lung spaces to close down, shrink and stiffen. I had to push myself to see past the branding, to try to once again see in the photograph the loveliness of the places themselves, the way they open one's imagination, stimulating reverie and reverence. But I had to work hard to consciously undo the process of "image transfer" that had already occurred for me.

If we are, then, to undo the carefully constructed attractiveness of deadly tobacco products in all countries and cultures, we cannot solely be concerned with educating consumers about the diseases tobacco causes, raising taxes and banning advertising. We must also identify tobacco company cultural invaders for what they are: invaders who distort and destroy meaning. Tobacco industry cultural appropriation is the essence of nihilism, propelling us toward a world where nothing matters more than profit for its own sake, and all else becomes mere instrument.

So let us celebrate, in this last month of the year, our reappropriation of things that matter. Let us celebrate the resistance of the cultural, the natural, the authentic life-world to the ruthless commodification of everything we value. Let us spend time with those we love, doing things that have meaning. This, too, is part of shaping a tobacco-free world.

Competing interests: REM owns one share each of Philip Morris/Altria, Philip Morris International and
Reynolds American tobacco company stock for research and advocacy purposes. REM also served as a consultant to the US Department of Justice in USA vs Philip Morris et al.

Tobacco Control 2009;18:425-426.

doi:10.1136/tc.2009.034488

\section{REFERENCES}

1. Shawl N. Appropriate cultural appropriation. http://www.irosf.com/q/zine/article/10087 laccessed 19 October 2009).

2. Simpson D. Philippines: Sacred and profane. Tob Control 2001;10:204.

3. McDaniel PA, Malone RE. Legitimizing disease promotion: the role of corporate credibility. Am J Pub Health 2009;99:452-61.

4. World Health Organization. WHO Report on the Global Tobacco Epidemic, 2008-The MPOWER package. http://www.who.int/tobacco/mpower/ mpower report full 2008.pdf (accessed 19 October 2009).

5. Richter J. Holding corporations accountable: corporate conduct, international codes, and citizen action. London, UK: Zed Books, 2001. 